\title{
Journal of Birjand University of Medical Sciences
}

Birjand University

of Medical Sciences

Case Report

\section{Undiagnosed celiac disease in a patient with polyarthritis}

\author{
$\underline{\text { Zeinab Saremi }}^{1}$, Tahereh Fakharian ${ }^{2}{ }^{2}$
}

\begin{abstract}
Celiac disease is one of the most common autoimmune diseases with a prevalence rate of $0.5-1 \%$ in the total population. Diagnosis has increased in recent years; however, many cases of the disease still seem to be diagnosed late. Although the rheumatic manifestations of celiac disease are not uncommon, they are often overlooked. A 30-year-old female patient referred to the rheumatology clinic of Valiasr Hospital, Birjand, Iran, with swelling of the fingers and knees joints. Despite treatment with corticosteroids and anti-rheumatic medications for the past two years that modulated the immune system, migratory inflammatory arthritis was still present. Serologic tests were performed on the patient, and she underwent endoscopy and duodenal biopsy. The celiac disease diagnosis was confirmed for the patient, and the joint symptoms improved significantly following a gluten-free diet. Rheumatologic manifestations of celiac disease can be the primary symptoms of the disease, and a gluten-free diet prescribed for these patients can relieve the symptoms to a large extent.
\end{abstract}

Keywords: Arthritis, Autoantibody, Celiac disease

Citation: Saremi Z, Fakharian T. [Undiagnosed celiac disease in a patient with polyarthritis]. J Birjand Univ Med Sci. 2020; 27(4): 392-396. [Persian]

DOI http://10.32592/JBirjandUnivMedSci.2020.27.4.108

Received: December 3, 2019

Accepted: April 11, 2020

\footnotetext{
${ }^{1}$ Department of Rheumatology, Faculty of Medicine, Birjand University of Medical Sciences, Birjand, Iran

${ }^{2}$ Department of Gastroenterology and Hepatology, Faculty of Medicine, Birjand University of Medical Sciences, Birjand, Iran
}

Corresponding author: Department of Rheumatology, Faculty of Medicine, Birjand University of Medical Sciences, Birjand, Iran Tel: +989155340380 


\title{
بيمارى سلياك تشخيص داده نشده در بيمار با بلى آرتريت
}

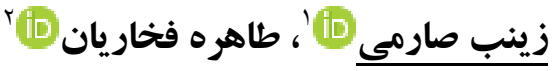

\section{جـكيله}

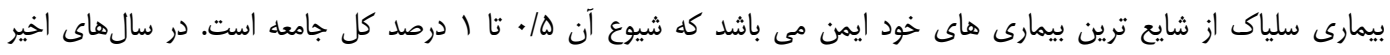

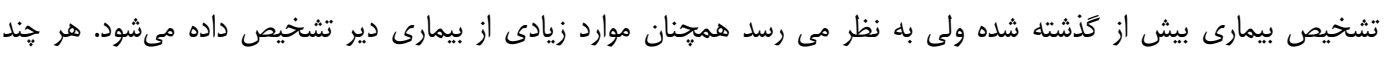

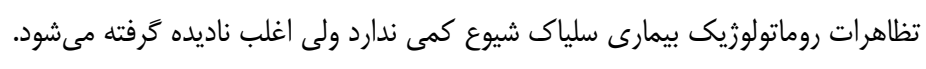

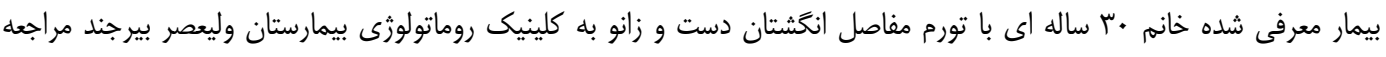

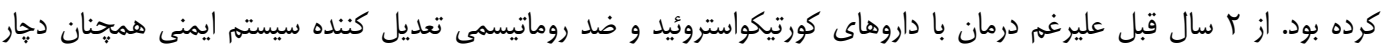

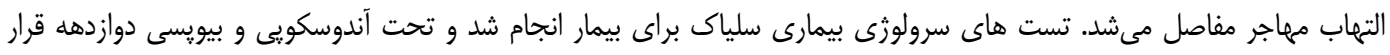

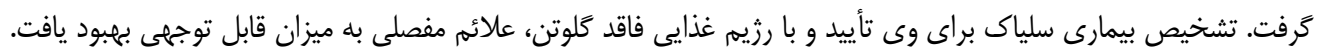

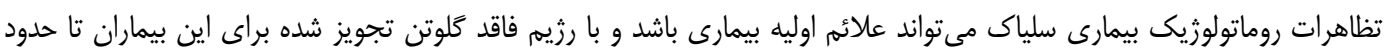
زيادى علائم برطرف خواهد شد.

$$
\text { وازههاى كليدى: آرتريت، اتوآنتى بادى، بيمارى سلياك }
$$

مجله علمى دانشكاه علوم يزشكى بيرجند. و وسرا؛

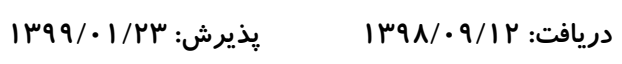

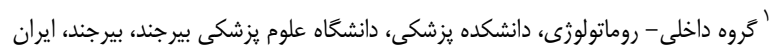

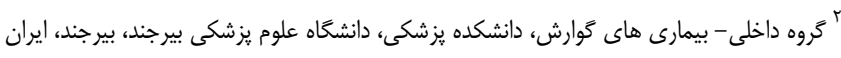

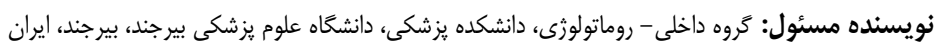

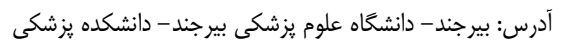

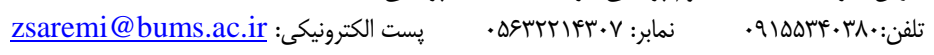




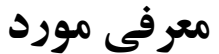

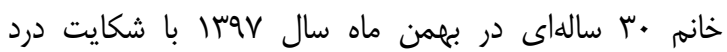
مفاصل دستها و زانوها كه از r سال قبل شروع بود به درمانغاه ماه

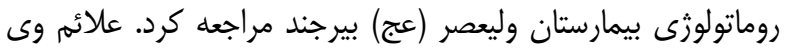

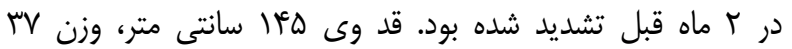

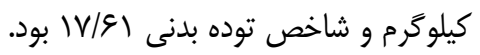

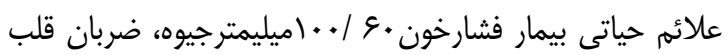

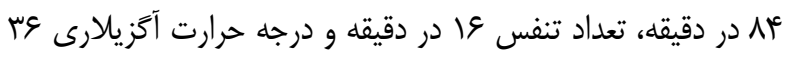

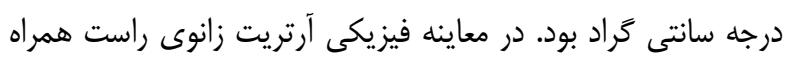
با افيورن مفصلى و محدوديت فلكسيون زانو مشاهده شد. آرتريت

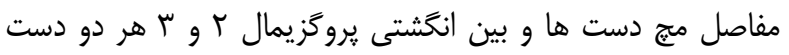

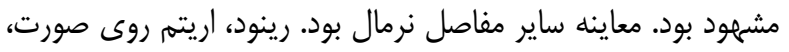

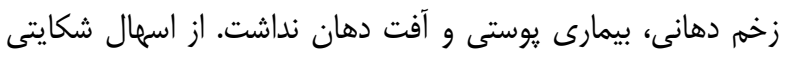

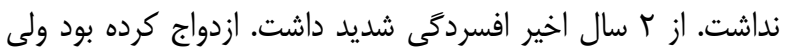

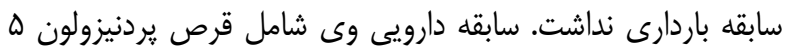

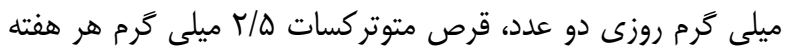

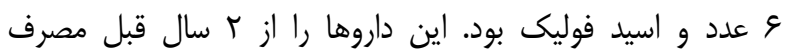
مى كرد ولى بهبودى در علائم وى ظاهر نشده بود. در سابقه فاميلى بيمارى خاصى را در فاميل درجه اول خود ذكر نمى كرد دل
بيمارى سلياك يك بيمارى خود ايمن است كه به دليل

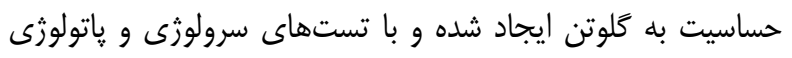

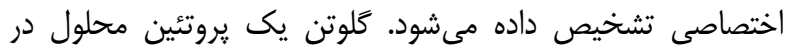

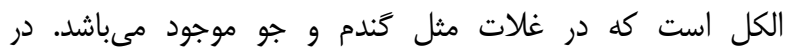
سالهاى اخير شيوع بيمارى به دليل روشهاى بهتر و دقيقتر تشخيصى بيشتر شده است (1). برخى اعلام كرده اند كه افزايش شيوع بيمارى به دليل رثيم

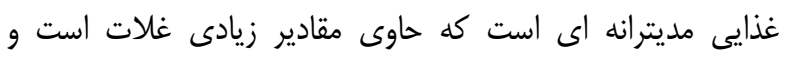

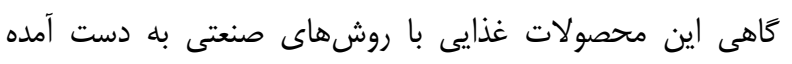

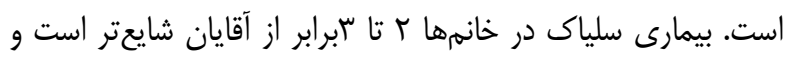

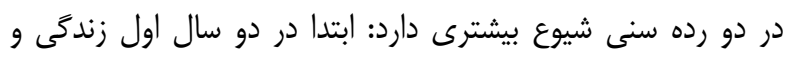

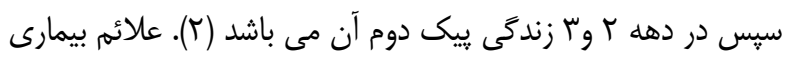

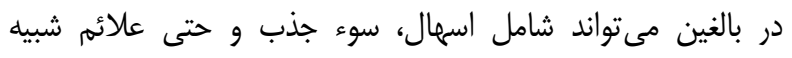
بيمارى روده تحريك يذير باشد. تظاهرات خارج روده اى بيمارى ناء

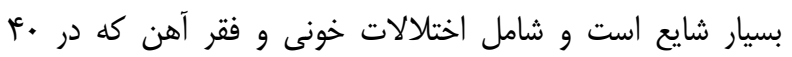
درصد بيماران ديده مىشود، افزايش آنزيمهاى كبدى، آفت دهان كه در • r درصد بيماران با سلياك تشخيص داده نشده كزارش شده است، اختلالات جنسى شامل نابارورى و يائسكى زودرس، اختلالات

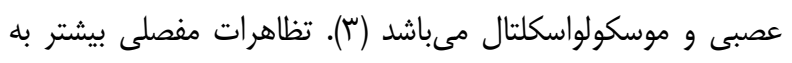
صورت كاهش دانسيته استخوان و استئويروز گزارش شده است. بهعلاوه مواردى از آرتريت و التهاب مفاصل، آرترالزى و دردهاى داى

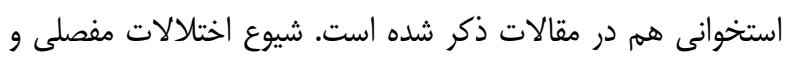

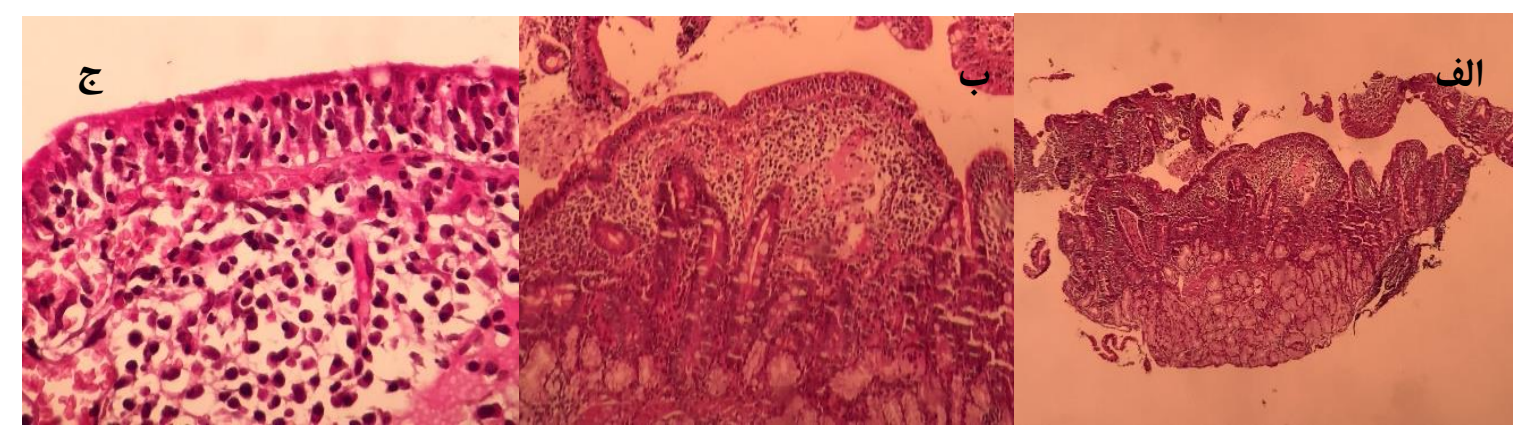

تصوير ا - الف و ب) پاتولوزى مخاط دوازدهه: تورم ويلى و هييرتروفى كريبت را نشان ميدهد ج) افزايش لنفوسيت هاى داخل ابي تليوم

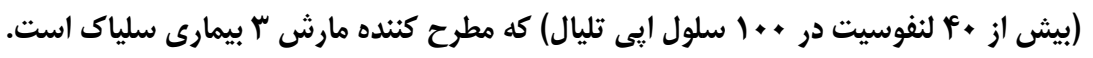


بيمارى سلياك فقط rrVدصد با علائم اسمال و سوء جذب و كاهش

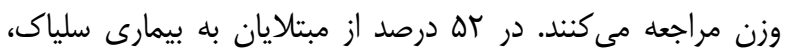
تظاهرات خارج روده اى (افزايش آنزيم هاى كبدى، يوكى استخوان، كم خونى، يبوست و علائم عصبى و يوستى) بروز يبيدا مى كنند (1).

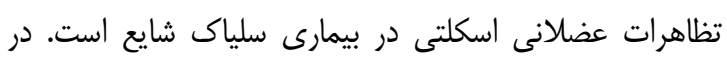

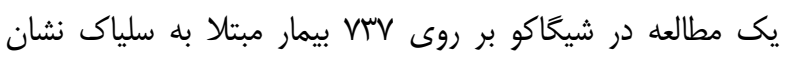
دادند كه در حدود ع| درصد بيماران علائم درد مفاصل؛ ها درصد

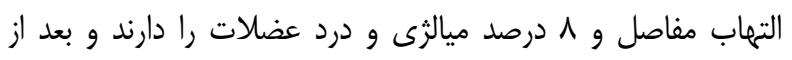

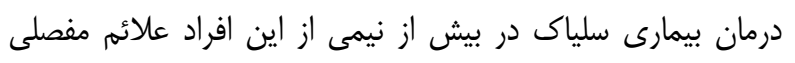

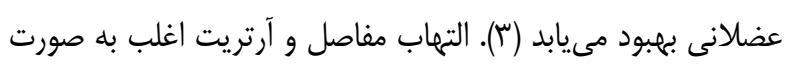
آرتريت حاد غير تخريبى بروز مىكند و مىتواند مفاصل محيطى يا ياني

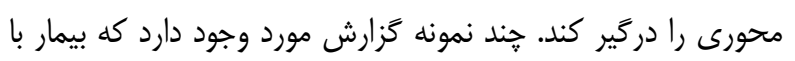

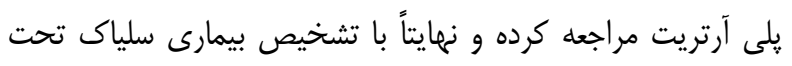

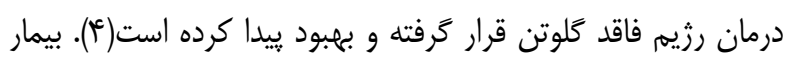

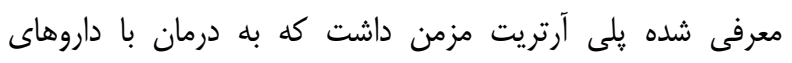
كورتيكواستروئيد و داروهاى ضد روماتيسمى تعديل كننده سيستم

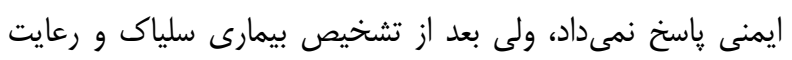

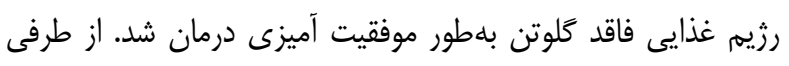

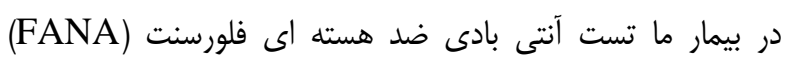
مثبت بود. شيوع مثبت شدن اين اتوآنتى بادى در مبتلايان به بيمارى

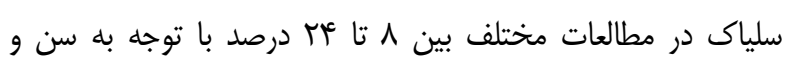
جنس جمعيت مورد مطالعه متغير است كه در اكثر موارد تيتر آن

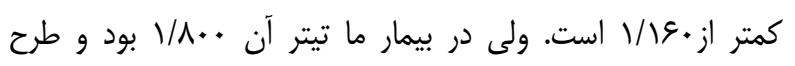
هموزن داشت. طرح هموثن FANA بيشتر در بيمارى لويوس

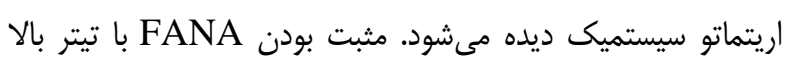

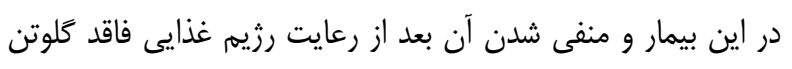

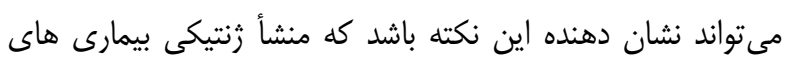

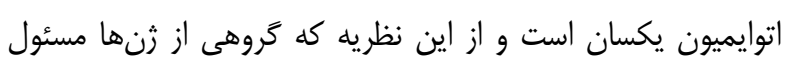

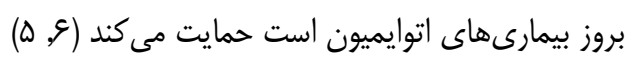

\section{نتايج پاراكلينيك}

تخليه مايع مفصل زانو انجام شد كه مايع با ويسكوزيته كاهش

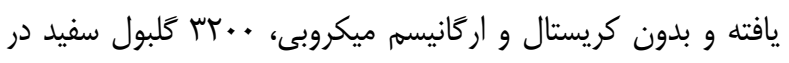
ميلى متر با ارجحيت سلولهاى جند هسته اي (•م درصد) خارج شد.

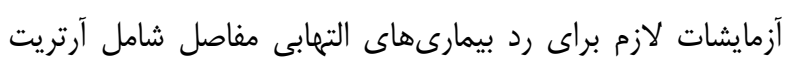

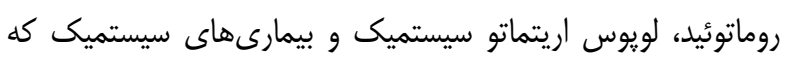

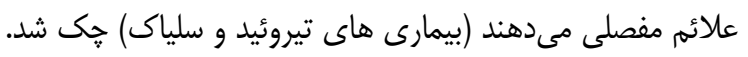

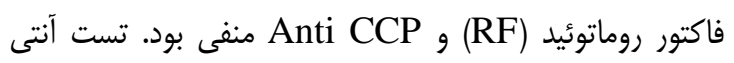

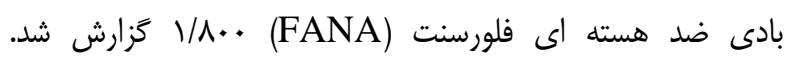

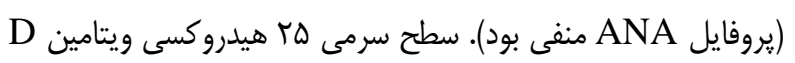
ه/A نانوگرم در ميلى ليتر و تست هاى تيروئيد؛ كبد و كليه نرمال

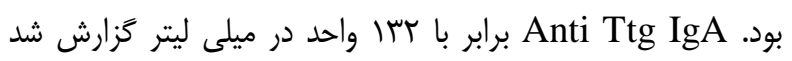

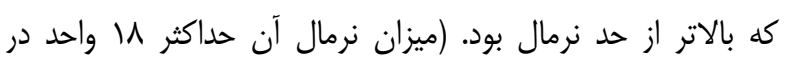

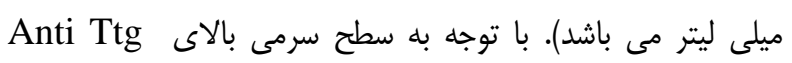

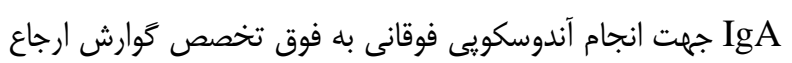

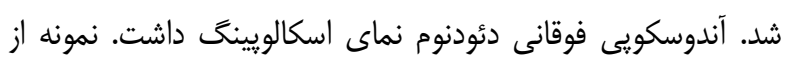
دوازدهه جهت تشخيص بيمارى سلياك گرفته شد. پياتولوزى

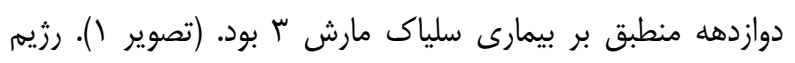

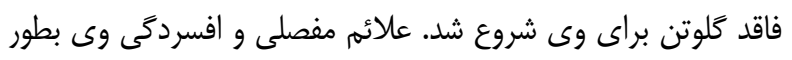
كامل برطرف و درمان آنتى روماتيسمى زمينه اى قطع گَرديد. بّ ماه

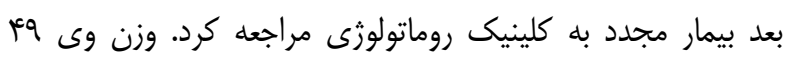

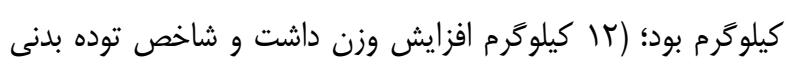

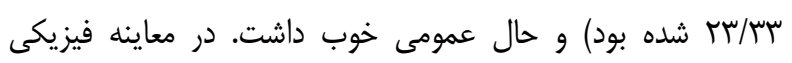
مفاصل آرتريت نداشت و نياز به تجويز داروى آنتى روماتيسمى نبود.

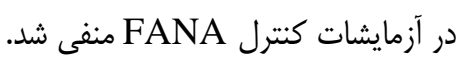

بيمارى سلياك مى تواند با توجه به وجود اسهال و اختلال رشد

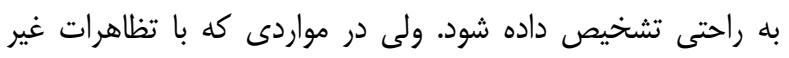

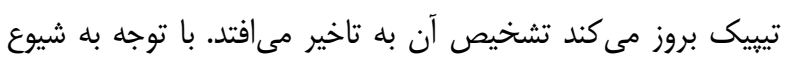

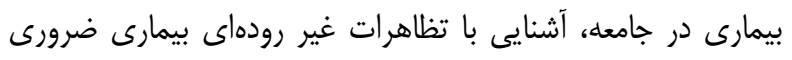
است. در مطالعات صورت كرفته مشخص شده است كه مبتلايان به به بهات 


\section{تقدير و تشكر}

در پِايان از زحمات اساتيد كَرامى جناب آقاى دكتر زردست كه

در تشخيص بيمارى همكارى نمودند و نيز از مركز تحقيقات بالينى

بيمارستان ولى عصر (عج) قدردانى مى خردد.

\section{تضاد منافع}

نويسندكان مقاله اعلام مى دارند كه هيج كونه تضاد منافعى در

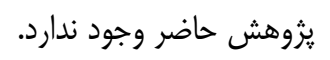

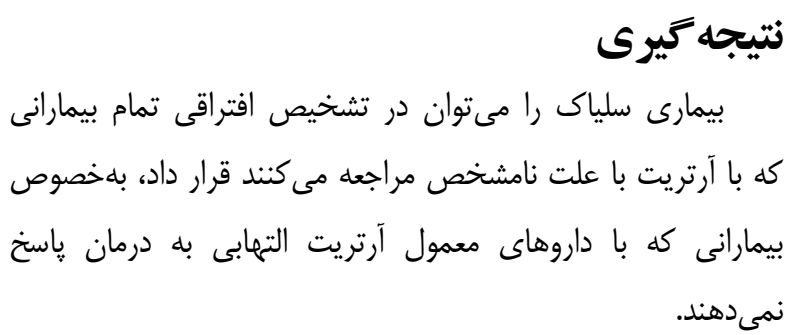

1- Caio G, Volta U, Sapone A, Leffler DA, De Giorgio R, Catassi C, et al. Celiac disease: a comprehensive current review. BMC Med. 2019; 17(1): 1-20. DOI: 10.1186/s12916-019-1380-z.

2- Ditah IC, Nadeau AM, Rubio-Tapia A, Marietta EV, Brantner TL, Camilleri MJ, et al. Trends and racial/ethnic disparities in gluten-sensitive problems in the United States: findings from the National Health and Nutrition Examination Surveys from 1988 to 2012. Am J Gastroenterol. 2015; 110(3): 455-61. DOI: 10.1038/ajg.2015.8

3- Nurminen S, Kivelä L, Huhtala H, Kaukinen K, Kurppa K. Extraintestinal manifestations were common in children with coeliac disease and were more prevalent in patients with more severe clinical and histological presentation. Acta Paediatr. 2019; 108(4): 681-7. DOI:10.1111/apa.14324

4- Efe C, Urün Y, Purnak T, Ozaslan E, Ozbalkan Z, Savass B, et al. Silent celiac disease presenting with polyarthritis. JCR: J Clin Rheumatol. 2010; 16(4): 195-6. DOI: 10.1097/RHU.0b013e3181dfcffd

5- Caglar E, Ugurlu S, Ozenoglu A, Can G, Kadioglu P, Dobrucali A, et al. Autoantibody frequency in celiac disease. Clinics. 2009; 64(12): 1195-200. DOI: 10.1590/S1807-59322009001200009.

6- Li YR, Li J, Zhao SD, Bradfield JP, Mentch FD, Maggadottir SM, et al. Meta-analysis of shared genetic architecture across ten pediatric autoimmune diseases. Nat Med. 2015; 21(9): 1018. DOI: 10.1038/nm.3933. 